\title{
Erratum to: Fibro-Osseous Lesions of the Craniofacial Bones: $\beta$-Catenin Immunohistochemical Analysis and CTNNB1 and APC Mutation Analysis
}

\author{
Andrew E. Horvai · Richard C. Jordan
}

Published online: 25 May 2014

(c) Springer Science+Business Media New York 2014

Erratum to: Head and Neck Pathol

DOI 10.1007/s12105-014-0535-7

Some of the amino acid positions are incorrect in this article. The correct positions, in the abstract, are Glu1317 instead of Glu1229 and Glu1536 instead of Tyr1475. The correct amino acid position, in the results section, is Glu1536 instead of Asp1536. The authors regret overlooking the error.

The online version of the original article can be found under doi:10.1007/s12105-014-0535-7.

A. E. Horvai $(\bowtie) \cdot$ R. C. Jordan Department of Pathology, University of California, San Francisco, 1600 Divisadero Street, B220,

San Francisco, CA 94115, USA

e-mail: Andrew.horvai@ucsf.edu

R. C. Jordan

Department of Orofacial Sciences, University of California,

San Francisco, 1701 Divisadero Street, Room 280,

Box 1790, San Francisco, CA 94143, USA 